pigments and of pharmaceuticals, while in 1955 an important step was taken in entering the nuclear energy field with the production of fuel elements.

Similarly the metallurgical activities were revived at Hanau and Pforzheim, and Degussa again took its place as one of the leading refiners and fabricators of gold, silver and the platinum metals under the guidance of Robert Hirtes and of Dr Ulrich Hoffmann and later of Erich Furler and Dr Hellmuth Schmidt.

In the field of research many contributions have been made to the knowledge of gold, silver and the platinum metals and their alloys-and of their applications in industry-under the leadership successively of Dr Alfred Boettcher, Dr Carl
Froehlich and Dr Otto Loebich. More recently, on a new site at Wolfgang near Frankfurt, a modern and well equipped laboratory for metallurgical research has been built, alongside a chemical research facility erected a little earlier, with the expressed intention of encouraging the interplay of ideas between chemists, physicists and metallurgists and the development of new types of industrial materials.

The centenary celebrations held in Frankfurt formed one of the last occasions on which the chairman, Dr Felix Prentzel, was to preside. After a long and distinguished period in this office, including the supervision of the more recent expansion programme, he is shortly to be succeeded by Mr Paul Ungerer.

\title{
The Sources and Composition of Prehistoric Gold
}

\section{INVESTIGATIONS BY EMISSION SPECTROSCOPY}

Since 1950 systematic investigations into prehistoric metallurgy have been carried out by the Arbeitsgemeinschaft für Metallurgie des Altertums bei dem Römisch-Germanischen Zentralmuseum at Mainz and most interesting results have emerged from the cooperation of chemists and archaeologists. Some 3,300 gold objects have now been studied by emission spectroscopy, and a review of the findings is given in a paper by A. Hartmann and E. Sangmeister (Angew. Chem., 1972, 84, (14), 668).

The objects come from hoards found all over Europe, from Spain and Ireland to Denmark and the Danube basin. Also included in the programme of analysis were samples of gold from European ore deposits in the hope that these might reveal where the gold was mined in prehistoric times. An initial examination of the gold ores showed that tin and platinum occur typically as minor impurities in secondary (alluvial) gold deposits but not in primary (mined) gold. This is due to the tendency of heavy minerals, such as native platinum and cassiterite, to concentrate with the gold during washing. Thus we have a simple means of checking the type of gold used for the prehistoric objects, since we can be sure that no refining process was used.

The analyses of the gold objects shows that from the Early Bronze Age to the Roman era almost all the objects were made from alluvial gold because of the invariable presence of tin. It can be inferred that primary gold ores were not worked systematically until well into Roman times. However, rather surprisingly, some of the earliest samples coming from the Copper Age and Early Bronze Age were of metal that did not contain tin. This metal has been identified as Gold $B$, and three explanations of its source are possible. First, the metal could have come from hand-picked nuggets which would be free of other minerals. Secondly, a source of tin-free alluvial gold might have existed that is now exhausted. Thirdly, the gold could have been imported from an area where mining was already established. Evaluation of the other minor constituents of these samples shows that they probably came from the Near East where, particularly in Egypt, gold mining was well established by 3000 B.c. The distribution map of the finds of Gold B shows mostly coastal sites which fit in with the possibility of sea trade links with the Eastern Mediterranean.

In the Early Bronze Age, Gold B, which normally contains less than 10 per cent silver, is replaced by an alloy containing, on average, 26 per cent silver. This alloy is known as Gold A3 and is alluvial in origin. Most of the finds of Gold A3 are concentrated in the middle Danube area. Primary gold ores found in this region near Brad in Romania are very similar in composition to Gold A3. These deposits can be assumed to be the source of the secondary deposits used in the Bronze Age which are now worked out. The gold from this area was exported as widely as Scandinavia, the Netherlands and possibly Brittany. It is hoped that further work will reveal whether it was also supplied to Mycenae, Troy and the Hittite Empire.

At the beginning of the second millenium B.C. a third type of metal, Gold $N$, alluvial in nature, with a rather higher than normal copper content of 2 per cent, was introduced. The source of this metal is not known although a large number of objects were made from it. It is possible that a rather rich mine existed in Eastern Europe but with the present international tensions this cannot be checked.

The distribution of the objects made from Gold $\mathrm{N}$, which are mostly found in Central and Northern Europe, Spain and the British Isles, is probably related to the westward migration of races from Eastern and Central Europe that is known to have occurred at this time.

By about 1000 B.C. up to 10 per cent copper was being intentionally added to Gold $N$, producing a warm coloured and somewhat harder alloy. This process was established first in the British Isles and only later in the rest of Europe. The reason for this is not fully understood.

Ch. J. R. 